\title{
Health literacy and glycemic control in patients with diabetes: a tertiary care center study in Brazil
}

\author{
Marilia B. Gomes', Luiza Harcar Muniz', Laura Gomes Nunes Melo', Marcela Haas Pizarro', \\ Bianca Senger Vasconcelos Barros ${ }^{1}$, Deborah Conte Santos ${ }^{1}$ and Carlos Antonio Negrato ${ }^{2 *}$
}

\begin{abstract}
Background: The primary objective of our study was to determine which factors influence health literacy $(\mathrm{HL})$ in patients with type 1 diabetes (T1D) and type 2 diabetes (T2D), and the secondary one was to evaluate the influence of HL on glycemic control.

Methods: This was an observational, cross-sectional study with 347 patients (144 with T1D and 203 with T2D), conducted between December 2014/December 2017. Data were obtained from medical records and/or questionnaire. The short test of Functional Health Literacy (S-TOFHLA) was used to evaluate HL.

Results: Age and years of school attendance were the most important variables associated with better performance in S-TOFHLA mainly in patients with T1D. A correlation between age and years of school attendance with S-TOFHLA score was observed in both groups of patients. After an unadjusted analysis, more patients with T1D presented adequate HL [119 (82.6\%) vs $87(44.8 \%, \mathrm{p}<0.001)]$. Patients with T1D had higher scores than patients with T2D $(84.4 \pm 21.4$ vs $61.6 \pm 26.8$ points, $p<0.001$ ), respectively. This difference did not persist after adjustment for age and years of school attendance (73.04 $\pm 2.14 \pm$ vs $70.04 \pm 1.76$ points) respectively, $p=0.348)$. No difference was found in HbA1c levels according to S-TOFHLA. All patients with T1D and HbA1c levels $<7.0 \%(53 \mathrm{mmol} / \mathrm{mol})$ had adequate $\mathrm{HL}$.

Conclusions: A considerable number of patients with either T1D or T2D did not have adequate HL. Overall, age and years of school attendance were the most important variables associated with better performance of S-TOFHLA. Although no difference was found in HbA1c levels according to S-TOFHLA, patients with T1D who self-reported as White, with more years of school attendance, and higher $\mathrm{HL}$ score reached more frequently a good glycemic control. Finally, in addition to therapeutic regimens, approaches on diabetes management should also include patients' $\mathrm{HL}$ evaluation along with psychological and social aspects.
\end{abstract}

Keywords: Type 1 diabetes, Type 2 diabetes, Glycemic control, Health literacy, Diabetes management

\section{Background}

Diabetes is a chronic disease with a prevalence that varies widely throughout the world and is continuously increasing $[1,2]$. Nowadays, intensive diabetes management

${ }^{*}$ Correspondence: carlosnegrato@uol.com.b

2 Medical Doctor Program, University of São Paulo-School of Dentistry, Bauru, São Paulo, Brazil

Full list of author information is available at the end of the article including insulin therapeutic regimens or therapies with oral agents, self-monitoring of blood glucose (SMBG), practice of regular physical activity and medical nutrition therapy are the basis of treatment for patients with either type 1 diabetes (T1D) or type 2 diabetes (T2D) [3]. These therapies are important to obtain and keep a satisfactory glycemic control and avoid diabetes-related chronic complications that result in very high direct and indirect costs and are associated with high rates of mortality [4,

c) The Author(s) 2020. This article is licensed under a Creative Commons Attribution 4.0 International License, which permits use, sharing, adaptation, distribution and reproduction in any medium or format, as long as you give appropriate credit to the original author(s) and the source, provide a link to the Creative Commons licence, and indicate if changes were made. The images or other third party material in this article are included in the article's Creative Commons licence, unless indicated otherwise in a credit line to the material. If material is not included in the article's Creative Commons licence and your intended use is not permitted by statutory regulation or exceeds the permitted use, you will need to obtain permission directly from the copyright holder. To view a copy of this licence, visit http://creativeco mmons.org/licenses/by/4.0/. The Creative Commons Public Domain Dedication waiver (http://creativecommons.org/publicdomain/ zero/1.0/) applies to the data made available in this article, unless otherwise stated in a credit line to the data. 
5]. Ever since the results of the UKPDS [6] and the Diabetes Control and Complications Trial (DCCT) and Epidemiology of Diabetes Interventions and Complications (EDIC) studies were brought up to light, showing that good glycemic control reduces the risk of diabetesrelated chronic complications [7], different intensive therapies were proposed for both groups of patients $[8$, 9]. However, to reach and maintain a good glycemic control is still a challenge in clinical practice, mainly among minorities [10]. In the US, the Exchange study has shown that only $64 \%$ and $43 \%$ of children and adolescents, met the glycemic control targets, respectively [11], while in Europe, the Eurodiab study has shown that only $16 \%$ of their patients had an adequate glycemic control [12]. Considering patients with T2D, the Discover study, an observational worldwide survey, showed that the majority of the patients were out of good glycemic control targets [13]. In previous Brazilian studies, only $13.2 \%$ of patients with T1D [14] and less than $50 \%$ of patients with T2D presented HbA1c at goal [15].

Moreover, many other factors can contribute to poor glycemic control in daily clinical practice such as poor or absent family support, social economic inequalities, poor continuous educational support regarding many aspects of diabetes as well as its management, inadequate literacy and cognitive dysfunction due to hypoglycemia or chronic hyperglycemia [16-20]. Health literacy (HL) and cognitive function should then be considered cornerstone tools for an adequate management of all chronic diseases including diabetes [21,22].

In Brazil, literacy is still a cumbersome problem. According to PNAD (Pesquisa Nacional por Amostra de Domicílios or National Household Sample Survey), 11.8 million (7.2\%) of Brazilians could be considered as illiterate [23]. Besides this, data from INAF (Indicador de Alfabetismo Funcional or Functional Literacy Indicator), evaluating the literate population, showed that about $27 \%$ were considered to be non-functionally literate [24]. Recently, the term HL was introduced in educational medical health programs and is defined as the ability to use any type of health information to take appropriate decisions and follow correctly treatments related to any type of disease [21]. Nowadays, HL is an important issue in diabetes management due to its high level of complexity $[25,26]$. In a recent review, the relationship between HL and diabetes included many aspects that are important for the management of the disease such as listening and speaking, writing and reading, and also the ability to understand and use numbers $[25,26]$. Although all the above mentioned skills could be indirectly related to glycemic control as well as to the evolution of diabetesrelated chronic complications, the results of some studies are still controversial because the best tool to evaluate
$\mathrm{HL}$, as well as the need to perform it in routine clinical care, are still undefined [26-38].

The test of Functional Health Literacy (TOFHLA) is commonly used in medical research in several countries, including Brazil, and has been considered a suitable tool to evaluate HL [27]. This test has three versions: the complete version, a 67-item, 22-min test evaluating reading comprehension and numeracy skills; the short version of TOFHLA (S-TOFHLA), a 40-item, 12-min test of numeracy skills (4-items) and reading and comprehension (36-items) [27]. According to the score obtained from TOFHLA, patients are classified as illiterate, literally inadequate or literate [27]. However, in developing countries in which a large number of people are still non-functionally literate, such as Brazil, it is important to establish the relationship between HL, educational level and some aspects of chronic diseases that could be relevant for its morbidity [21, 39]. The TOFHLA comprises questions related to self-efficacy, that is an important tool for diabetes management that is related to glycemic control.

The above mentioned factors could be considered barriers, sometimes invisible for diabetes teams, hindering the achievement of good glycemic control in daily routine clinical practice and thus, increasing the risk for diabetes-related chronic complications.

The primary aim of our study was to determine which factors may influence HL in patients with diabetes, and the secondary one, to verify the influence of HL on glycemic control.

\section{Research design, study participants and methods}

This was an observational, cross-sectional study, conducted at the Diabetes Unit from Rio de Janeiro's State University (UERJ) between December 2014 and December 2017. All consecutive patients with T1D or T2D in use of oral drugs as well as under insulin therapy, attending the Diabetes Unit who agreed to participate, were enrolled in the study. This study was approved by the ethics committee of Hospital Universitário Pedro Ernesto. Written informed consent was obtained from all patients. The inclusion criteria were patients diagnosed with either T1D or T2D according to ADA's criteria [3], aged 19 to 80 years, followed at the outpatient clinic for at least 6 months. The exclusion criteria were the presence of cerebrovascular disease, pregnancy, history of acute infection in the previous 3 months, severe hypoglycemia or diabetic ketoacidosis in the last month, blindness, mental health disease and any disease that could interfere with the accuracy of the answers.

The following variables were assessed using a questionnaire during a clinical visit: current age, age at diagnosis, diabetes duration, years of school attendance, economic 
status, self-reported color-race, systolic and diastolic blood pressure, antihyperglycemic therapeutic regimens, use of statins and anti-hypertensive drugs, smoking and drinking habits. Body mass index (BMI) was determined by dividing an individual's weight $(\mathrm{kg})$ by the square of the height $\left(\mathrm{m}^{2}\right)$.

We have adopted the ADA's goals for adequate metabolic and clinical control: good glycemic control was defined as $\mathrm{HbAlc}<7 \%$ (53 mmol/mol) [40]. Poor glycemic control was arbitrarily defined as HbA1c $\geq 9 \%$ (75 mmol $/ \mathrm{mol})$. HbA1c, creatinine, triglycerides, total cholesterol, high-density lipoprotein (HDL) cholesterol, low-density lipoprotein (LDL) cholesterol levels were measured during the clinical visit or were obtained from the patients' medical records. HbA1c was measured using high-performance liquid chromatography (HPLC, Bio-Rad Laboratories, Hercules, California, USA). Creatinine, HDL cholesterol, total cholesterol, and triglycerides were measured using enzymatic techniques. Smoking was defined as the current use of more than one cigarette per day at the time of the interview and drinking was defined according to the guidelines of the World Health Organization (WHO) [41].

\section{Measurement of health literacy}

The evaluation of HL was carried out by a trained researcher for the application of the used instruments in an adequate room with attenuation of external noise at Diabetes Unit. The following tests were applied to evaluate HL: the short version of TOFHLA (S-TOFHLA), a 40-item, 12-min test of numeracy skills (4-item, 28 points) and reading and comprehension (36-item, 72 points) [42]. Results for S-TOFHLA, which maximum score was 100 points (1 point for each correct answer), were categorized into illiteracy ( $0-53$ correct answers); inadequate literacy (54-66 correct answers) and adequate literacy (67-100 correct answers) [42]. S-TOFHLA tests have been used in Portuguese language [33]. The tests were performed exclusively in patients with capillary glycemia $(\mathrm{CG}) \geq 100 \mathrm{mg} / \mathrm{dl}$ before the beginning of the tests. Patients with CG $<100 \mathrm{mg} / \mathrm{dl}$ were instructed to eat a light meal with carbohydrates and wait for a re-test of CG to proceed with the evaluation or had the evaluation remarked. At this time we also tested the visual acuity by the Rosenbaum Pocket Vision Screener test [43]. Patients with abnormal visual acuity were tested for card reading and, when considered able, performed the tests.

\section{Economic status definition}

Economic status was defined according to the Brazilian Economic Classification Criteria, which also categorize education as illiterate/incomplete primary education, complete primary education/incomplete secondary education, complete secondary education/ incomplete high school, complete high school/some college or complete college education [22]. The following classes of economic status were considered: high, middle, low and very low.

\section{Statistical analysis}

Firstly, an exploratory analysis was carried out. Data are presented as the means $( \pm \mathrm{SD})$ or mean \pm standard error (SE) for ANCOVA data or medians (minimum-maximum) for continuous variables and numbers (relative frequencies) for discrete variables. Comparisons between independent continuous variables were performed using independent, two-sided $t$-tests or Mann-Whitney when indicated. ANOVA with Zidak correction, was used as indicated. Two-sided Z-tests were used for comparisons between discrete variables. Bivariate Pearson correlation was performed between S-TOFHLA score as continuous variable and demographic and laboratorial data with further analysis adjusted for years of school attendance (partial correlation). Forward Wald stepwise multivariate logistic regression analysis was performed with $\mathrm{HbA} 1 \mathrm{c}<7.0 \%(53 \mathrm{mmol} / \mathrm{mol})$ and $\mathrm{HbA} 1 \mathrm{c} \geq 9.0 \%$ $(75 \mathrm{mmol} / \mathrm{mol}$ ) as the dependent (outcome) variables. Other predictive variables, such as self-reported colorrace, age, years of school attendance, gender and duration of diabetes were controlled in the analysis. In this latter model we added S-TOFHLA separately from years of school attendance due to its interaction. ANCOVA was performed with total S-TOFHLA score as dependent variable and with age and years of school attendance as covariates for adjustment. Multivariate logistic analysis was also performed with S-TOFHLA adequate and inadequate as dependent variable and type of diabetes, duration of diabetes, self-reported color-race, age and years of school attendance as independent variables. In these models the Nagelkerke R-squared value was also calculated. Analysis were performed using SPSS version 17.0 (SPSS, Inc., Chicago, Illinois). Odds ratios with 95\% CIs were expressed as indicated. A two-sided $p$ value less than 0.05 was considered significant.

\section{Results \\ Overview of the demographic and clinical data of the studied population}

Table 1 shows the clinical and demographic data of the studied population. Only $5(3.7 \%)$ and $4(2.0 \%)$ patients with T1D and T2D, presented $\mathrm{CG}<100 \mathrm{mg} / \mathrm{dl}$, respectively, but no one presented symptoms of hypoglycemia. These patients were re-tested for CG, and when the results were over $100 \mathrm{mg} / \mathrm{dl}$, they were evaluated. All the patients with T1D had visual acuity considered adequate to perform the test (S-TOFHLA), but five (2.5\%) patients 
Table 1 Demographic, clinical and laboratory data of the studied population

\begin{tabular}{|c|c|c|}
\hline Variables & T1D & T2D \\
\hline Age, years & $37.5 \pm 12.5$ & $59.7 \pm 10.4$ \\
\hline \multicolumn{3}{|l|}{ Age, n (\%) (years) } \\
\hline$<25$ & $29(20.1)$ & $2(1.0)$ \\
\hline $25-44$ & $67(46.5)$ & 16(7.9) \\
\hline $45-64$ & $46(31.9)$ & $123(60.6)$ \\
\hline$\geq 65$ & $2(1.0)$ & $62(30.5)$ \\
\hline \multicolumn{3}{|l|}{ Gender, n (\%) } \\
\hline Male & $63(43.7)$ & $71(37.9)$ \\
\hline Female & $81(56.3)$ & $132(65)$ \\
\hline \multicolumn{3}{|l|}{ Self-reported color-race, n (\%) ${ }^{\mathrm{a}}$} \\
\hline White & $73(50.7)$ & $77(37.9)$ \\
\hline Non-White & $71(49.3)$ & $126(62.1)$ \\
\hline Years of school attendance & $12.4 \pm 3.1$ & $8.4 \pm 4.4$ \\
\hline \multicolumn{3}{|l|}{ Economic status $^{\mathrm{b}}$} \\
\hline Low & $95(66.0)$ & $123(60.6)$ \\
\hline Very low & $10(6.9)$ & $34(16.7)$ \\
\hline Medium & $31(21.5)$ & $18(8.9)$ \\
\hline BMI $\left(\mathrm{kg} / \mathrm{m}^{2}\right)$ & $24.6 \pm 4.2$ & $29.9 \pm 5.2$ \\
\hline Initial CG (mg/dl) & $195.8 \pm 81.4$ & $184.1 \pm 64.8$ \\
\hline Final CG (mg/dl) & $172.7 \pm 89.7$ & $174.1 \pm 70.6$ \\
\hline HbA1c (\%) & $8.9 \pm 1.9$ & $8.1 \pm 3.2$ \\
\hline$<7.0 \mathrm{n}(\%)$ & $16(11.8)$ & $56(26.6)$ \\
\hline$\geq 9.0$ n (\%) & $63(46.3)$ & $60(29.6)$ \\
\hline $\mathrm{HbA} 1 \mathrm{c}, \mathrm{mmol} / \mathrm{mol}$ & $74.5 \pm 21.0$ & $65.3 \pm 19.5$ \\
\hline Smokers, years; n (\%) & $15(7.5)$ & $33(16.2)$ \\
\hline Drinkers, years; n (\%) & $25(17.4)$ & $44(21.6)$ \\
\hline \multicolumn{3}{|l|}{ Diabetes treatment; years, n (\%) } \\
\hline Oral drugs ${ }^{c}$ & $48(23.9)$ & $190(93.5)$ \\
\hline Antihypertensives & $40(27.8)$ & $130(64.0)$ \\
\hline Insulin & $144(100.0)$ & $92(45.3)$ \\
\hline Statins & $35(24.3)$ & $124(61.1)$ \\
\hline
\end{tabular}

T1D Type 1 diabetes, T2D Type 2 diabetes. Data are presented as $n$ (\%) or means (standard deviation), BMI body mass index, CG capillary glycemia

${ }^{a}$ Non-White (Mulattos and Blacks)

b Missing: 8 (5.6\%) for T1D and 28 (13.8\%) for T2D

c The oral drug used by patiens with T1D was metformin

with T2D presented an abnormal visual acuity. These patients did not perform the test.

\section{Demographic, clinical and laboratory data of the studied population stratified according to S-TOFHLA}

All patients with either T1D $(\mathrm{n}=5 ; 3.5 \%)$ and T2D $(\mathrm{n}=24 ; 12.4 \%)$ with inadequate literacy S-TOFHLA were considered as having illiteracy in S-TOFHLA. Patients with T1D had higher scores than patients with T2D $(84.4 \pm 21.4$ vs $61.6 \pm 26.8$ points, $\mathrm{p}<0.001)$, respectively. This difference did not persist after adjustment for age and years of school attendance $(73.04 \pm 2.14 \pm$ vs $70.04 \pm 1.76$ points $)$ respectively, $\mathrm{p}=0.348$. The unadjusted time required to complete the S-TOFHLA was longer in patients with T2D compared to patients with T1D $(9.4 \pm 1.8$ vs $7.7 \pm 2.1 \mathrm{~min}$, $\mathrm{p}<0.001$ ), respectively. This difference did not persist after adjustment for age and years of school attendance $(8.75 \pm 0.17$ vs $8.67 \pm 0.14, \mathrm{p}=0.757)$, respectively. Unadjusted analysis showed that more patients with T1D were considered literate than patients with T2D [119 (82.6\%) vs $87(44.8 \%), \mathrm{p}<0.001]$, respectively, and have reached the maximum score of 100 points than patients with T2D [51 (79.7\%) vs $13(20.3 \%), \mathrm{p}<0.001$ ], respectively.

Considering the part of S-TOFHLA which evaluated numeracy skills, patients with T1D had higher scores than patients with T2D $(23.0 \pm 7.2$ vs $20.3 \pm 7.6$ points; $\mathrm{p}=0.001$ ), respectively. More patients with T1D reached the maximum score of 28 points than patients with T2D [84 (58.3\%) vs 69 (34.0\%); p < 0.001], respectively. The time required to complete this part of S-TOFHLA was longer in patients with T2D compared to patients with T1D $(2.9 \pm 1.2$ vs $2.3 \pm 0.9 \mathrm{~min}$, $\mathrm{p}<0.001$ ), respectively. Considering the part of S-TOFHLA which evaluated reading and comprehension, patients with T1D had a higher score than patients with T2D $(61.4 \pm 16.1$ vs $41.3 \pm 21.8$ points; $\mathrm{p}<0.001)$, respectively. More patients with T1D reached the maximum score of 72 points than patients with T2D, [66 (45.8\%) vs $21(10.3 \%) ; \mathrm{p}<0.001$ ], respectively. In patients with T1D the total score of S-TOFHLA was not associated with gender and self-reported color-race but in patients with T2D a higher score of S-TOFHLA was observed in patients who self-reported as White $(70.9 \pm 24.1$ vs $55.9 \pm 27.1 ; \mathrm{p}<0.001)$, respectively. No association with gender was noted in patients with T2D. No difference was noted in the average HbA1c in patients with either T1D or T2D, either literate or illiterate. The demographic, clinical and laboratory data (glycemic control) stratified according to S-TOFHLA are described in Table 2.

The number and proportion of patients who answered correctly each question of both domains of S-TOFHLA are described in Table 3. The time required to complete this part of S-TOFHLA was longer in patients with T2D compared with patients with T1D $(6.6 \pm 0.9$ vs $5.4 \pm 1.5 \mathrm{~min}, \mathrm{p}<0.001)$, respectively. More patients with T1D with adequate HL had HbA1c levels $<7.0 \%$ $(53 \mathrm{mmol} / \mathrm{mol})$ than patients with inadequate HL [16 $(100 \%)$ vs 49 (77.8\%); $p=0.038]$, respectively. These patients had a higher score in TOFHLA, $(94.7 \pm 8.2$ vs $81.5 \pm 24.2, \mathrm{p}=0.03)$, respectively. 
Table 2 Demographic, clinical and laboratory data stratified according to S-TOFHLA

\begin{tabular}{|c|c|c|c|}
\hline \multicolumn{4}{|l|}{ S-TOFHLA } \\
\hline Variables & Literate & Illiterate & p-value \\
\hline \multicolumn{4}{|l|}{ T1D } \\
\hline & $N=119(82.6 \%)$ & $N=25(17.4 \%)$ & \\
\hline Age, years & $36.5 \pm 12.3$ & $42.2 \pm 12.1$ & 0.04 \\
\hline Gender, F, n (\%) & $70(86.4)$ & $11(13.6)$ & 0.17 \\
\hline Duration of diabetes, years & $18.3 \pm 10.2$ & $19.0 \pm 10.0$ & 0.70 \\
\hline \multicolumn{3}{|l|}{ Self-reported color-race, n (\%) } & 0.80 \\
\hline White & $61(83.6)$ & $12(16.4)$ & \\
\hline Non White ${ }^{a}$ & $58(81.7)$ & $13(18.3)$ & \\
\hline Years of study & $13.1 \pm 2.8$ & $9.3 \pm 2.9$ & $<0.001$ \\
\hline $\mathrm{HbA1c}(\%)$ & $8.9 \pm 1.9$ & $9.3 \pm 1.6$ & 0.30 \\
\hline $\mathrm{HbA1c}(\mathrm{mmol} / \mathrm{mol})$ & $73.8 \pm 21.7$ & $77.9 \pm 17.5$ & \\
\hline \multicolumn{4}{|l|}{$\mathrm{T} 2 \mathrm{D}^{\mathrm{b}}$} \\
\hline & $N=87(42.9)$ & $N=107(52.7)$ & \\
\hline Age, years & $55.9 \pm 10.6$ & $62.2 \pm 9.6$ & $<0.001$ \\
\hline Gender, F, n (\%) & $59(46.5)$ & $68(53.5)$ & 0.30 \\
\hline Duration of diabetes, years & $11.8 \pm 7.5$ & $16.5 \pm 9.7$ & $<0.001$ \\
\hline \multicolumn{3}{|c|}{ Self-reported color-race, n (\%) } & $<0.001$ \\
\hline White & $41(56.2)$ & $32(43.8)$ & \\
\hline Non White & $46(38.0)$ & $75(62)$ & \\
\hline Years of study & $10.9 \pm 3.9$ & $7.1 \pm 3.7$ & $<0.001$ \\
\hline $\mathrm{HbA} 1 \mathrm{c}$ & $8.3 \pm 1.9$ & $8.0 \pm 1.7$ & 0.15 \\
\hline $\mathrm{HbA} 1 \mathrm{c}(\mathrm{mmol} / \mathrm{mol})$ & $67.7 \pm 20.8$ & $63.6 \pm 18.7$ & \\
\hline
\end{tabular}

T1D type 1 diabetes, T2D type 2 diabetes

a Non-White (Mulattos and Blacks)

b Five patients were excluded from S-TOFHLA for inadequate visual acuity and four patients missed their appointment

Table 3 Number and proportion of patients who answered correctly the domains of the S-TOFHLA test

\begin{tabular}{lll}
\hline $\begin{array}{l}\text { Variables } \\
\text { Numeracy items: }\end{array}$ & T1D & T2D \\
& N=144 & N=194 \\
\hline Table medication every 6 $\mathrm{h}$ & $115(79.9)$ & $139(71.6)$ \\
Normal blood sugar & $116(80.6)$ & $162(83.5)$ \\
Appointment & $123(85.4)$ & $120(61.9)$ \\
Table medication before lunch & $120(83.3)$ & $141(72.7)$ \\
Reading comprehension (points) & & \\
0-18 & $3(2.1)$ & $37(19.1)$ \\
19-36 & $15(10.4)$ & $51(26.3)$ \\
37-55 & $20(13.9)$ & $42(21.6)$ \\
56-72 & $106(73.6)$ & $64(33.0)$ \\
\hline
\end{tabular}

Correlation between total S-TOFHLA score and demographic, clinical and laboratory data

Considering the group of patients with T1D, a correlation was observed between S-TOFHLA score and age $(\mathrm{r}=-0.24 ; \mathrm{p}=0.004)$, age at diagnosis $(\mathrm{r}=-0.22$; $\mathrm{p}=0.006)$ and years of school attendance $(\mathrm{r}=0.51$; $\mathrm{P}<0.001)$. The partial correlation coefficient between age and S-TOFHLA score persisted when controlling for the effect of years of school attendance $(r=-0.176 ; p=0.04)$ but did not persist for age at diagnosis. No correlation was observed with duration of diabetes and HbA1c levels. No correlation was noted between the score of S-TOFHLA test domains (numeracy skills, reading and comprehension) with HbA1c levels and CG at the beginning and at the end of the test.

Considering the group of patients with T2D, a correlation was observed between S-TOFHLA score with age $(\mathrm{r}=-0.33 ; \mathrm{p}=0.004)$, and with years of school attendance $(r=0,53 ; p<0001)$. The partial correlation coefficient between age and S-TOFHLA score persisted when controlling for the effect of years of school attendance $(\mathrm{r}=-0.22 ; \mathrm{p}=0.01)$. No correlation was observed with duration of diabetes and HbA1c levels. No correlation was also noted between the score of S-TOFHLA domains (numeracy skills, reading and comprehension) and HbA1c levels.

\section{Multivariate analysis with S-TOFHLA adequate and inadequate literacy as dependent variable} Multivariate analysis performed with adequate and inadequate literacy S-TOFHLA as dependent variables, showed that all the independent variables which entered in the model even after adjustment could explain only 45.5\% (Nagelkerke R-squared) of a given patient reaching an inadequate S-TOFHLA. The independent variables associated with inadequate S-TOFHLA were lower years of study $[\mathrm{B}=-0.282 ; \mathrm{OR}=0.754 \quad(0.696-0.817)$, $\mathrm{p}<0.001]$ and higher age $[\mathrm{B}=0.043 ; \mathrm{OR}=1.044 \mathrm{CI} 95 \%$ $(1.022-1.067 \mathrm{p}<0.001)]$. Type of diabetes, self-reported color-race and duration of diabetes did not reach statistical significance.

\section{Multivariate analysis in patients with type 1 diabetes with $\mathrm{HbA1C}$ at goal as the dependent variable}

Multivariate analysis performed with $\mathrm{HbA1c}$ at goal and HbA1c $\geq 9.0 \%(75 \mathrm{mmol} / \mathrm{mol})$ as dependent variable, showed that all the independent variables which entered in the model even after adjustment could explain only 21.3\% (Nagelkerke R-squared) of a given patient reaching the goal for HbA1c. In the model with S-TOFHLA as independent variable, $\mathrm{HbA1c}$ at goal was associated with White self-reported color-race $[\mathrm{B}=1.207 ; \mathrm{OR}=3.354$ CI 95\% (1.004-11.205), $\mathrm{p}=0.049]$ and had a tendency to be associated with $\mathrm{HL}[\mathrm{B}=0.055 ; \mathrm{OR}=1.057 \mathrm{CI} 95 \%$ (0.99-1.123), $\mathrm{p}=0.07]$. In the model with years of school attendance as independent variable, HbA1c at goal was 
associated with years of school attendance $[\mathrm{B}=-0.26$, $\mathrm{OR}=0.771(0.623-0.995), \mathrm{p}=0.017]$.

\section{Multivariate analysis in patients with type 2 diabetes with $\mathrm{HbA} 1 \mathrm{c}$ at goal as the dependent variable}

Multivariate analysis performed with HbA1c at goal and $\mathrm{HbA} 1 \mathrm{c} \geq 9.0 \%(75 \mathrm{mmol} / \mathrm{mol})$ as dependent variables, showed that no independent variables which entered in the model, even after adjustment, reached statistical significance or a tendency.

\section{Discussion}

Our study, conducted in a tertiary care center, showed that a considerable number of patients with either T1D or T2D did not have adequate HL. Our results have shown that the independent variables associated with inadequate S-TOFHLA were lower years of school attendance and higher age. However, after adjustment for age and years of school attendance, type of diabetes, self-reported color-race and duration of diabetes did not reach statistical significance. S-TOFHLA score was related to HbA1c levels only in patients with T1D. We found that all patients with T1D and $\mathrm{HbA} 1 \mathrm{c}<7.0 \%(53 \mathrm{mmol} / \mathrm{mol})$ had adequate HL.

Currently, diabetes management, including its treatment is very complex requiring special HL skills related to numeracy as well to reading and comprehension, and both could be considered important tools to help patients to take appropriate health decisions. Many factors may influence HL such as age, years of school attendance, ethnicity, socioeconomic status and psychological distress.

Considering the general population, inadequate HL has been found to be very frequent worldwide $[29,33]$ and up to this moment, no method can be considered as the gold standard for its measurement. So far, several instruments were used for the assessment of HL in patients with diabetes, including the S-TOFHLA, used in the present study $[32,36]$. It is important to note that most of the included studies were cross-sectional with insufficient or low level of evidence [26].

Our data showed that diabetes per se did not influence the results of S-TOFHLA, but glycemic control was influenced by the level of literacy, according to the scores obtained through the application of S-TOFHLA. However, this finding must be viewed with caution as well as its relation with the higher prevalence of inadequate HL among patients with T2D compared with patients having T1D, probably due to higher years of school attendance found in this latter group and the higher age found in patients with T2D. We do think that only future prospective studies could answer if diabetes, either T1D or T2D, has any impact on HL.
We have found that almost $18 \%$ of young patients with T1D were considered to have inadequate HL in comparison to $55.2 \%$ of the patients with T2D. The prevalence of inadequate HL, independent of the methods of measurement, among patients with T2D varies from $45.0 \%$ in Southeast of Brazil [44] to $65.9 \%$ in Northeast of Brazil [32] and from 10 to $69 \%$ in USA $[25,29,36]$. This fact shows that HL could be related to regional differences in education approaches, socioeconomic status, age, as well as to different characteristics of the diabetes care center included in the study. Similar to our data, in the majority of the above-mentioned studies, the most important variables associated with HL were years of school attendance and age. In the present study, performed with an admixed population, patients with T2D who self-reported as White, outperformed those who self-reported as non-White. A study conducted in the USA addressing only ethnic minorities did not find an association between HL, ethnicity and self-efficacy [37]. However, this topic is still controversial mainly due to different study designs and studied populations [29, 31, 32, 36, 39].

Few studies have been conducted exclusively with T1D or their caregivers [28, 30, 34, 38]. In our study, the prevalence of inadequate HL was $18 \%$ and it was lower than that reported in Pakistan, which was 67.2\% [28] and United Kingdom (UK), which was 75\% [30]. These conflicting results could be related to differences in educational level, age and socioeconomic status of the patients included in the studies as well as to different criteria used to define HL. In the present study, although we did not observe a correlation between HL and HbA1c, all the patients with $\mathrm{HbA} 1 \mathrm{c}<7.0 \%(53 \mathrm{mmol} / \mathrm{mol})$ were literate, similarly to the findings from Pakistan [28]. Similar to our data concerning patients with T1D, a study that evaluated HL in children with T1D and their mothers did not find a correlation between HbA1c and HL of the children, but this was found regarding mothers' HL [34]. Using the Diabetes Numeracy Test (DNT) in adolescents with T1D, a negative relationship was observed between the score and HbA1c [38]. The DNT include specific questions about sliding scale of insulin dosing, blood glucose monitoring, carbohydrate counting and exercise which are important tools for diabetes management. These questions are not addressed in S-TOFHLA. A study conducted in UK using the UK Adult Core Curriculum to asses literacy and numeracy skills showed an association between levels of HbA1c and numeracy scores but this association was not observed with literacy scores [30]. The above-mentioned facts point out that the evaluation of HL probably should be performed by different tools according to the type of diabetes as well as to the therapeutic regimens. 
The major strength of our study is that we have performed the S-TOFHLA in all patients in the same context and in the same conditions within the diabetes center. Another point is that our population was from different self-reported color-race and socioeconomic background similar to the general Brazilian population.

We have also to address some limitations of our study. First, taking into account that our study was cross-sectional, we can only infer associations; so no causal relationship between the S-TOFHLA and glycemic control could be concluded. Secondly, some relevant points for achieving adequate glycemic control were not evaluated such as diabetes self-efficacy, psychological factors, poor family support and adherence to diabetes treatment. In a recent study conducted in Brazil with patients with T1D, depression was associated with high levels of HbA1c [45]. Thirdly, the lower number of patients with good glycemic control in our sample could have influenced our results. However, it is important to note that the latter fact was also found in other studies involving patients with diabetes in Brazil $[14,15,45]$. Finally, the lack of a control population matched for years of school attendance could have also compromised our results. However, few studies have been done with both populations, mainly with patients having T1D.

\section{Conclusion}

In conclusion, in our study, a considerable number of patients with either T1D or T2D did not have adequate HL when evaluated by S-TOFHLA test. Overall, age and years of school attendance were the most important variables associated with better performance of the S-TOFHLA. In general, patients with T1D outperformed those with T2D. Although the majority of the patients did not present a good glycemic control, patients with T1D who had adequate $\mathrm{HL}$ reached more frequently $\mathrm{HbA1c}$ levels $<7 \%(53 \mathrm{mmol} / \mathrm{mol})$. Finally, in addition to therapeutic regimens, an approach on diabetes management should also include patients' HL evaluation together with psychological and social aspects aiming to improve glycemic control and avoiding short and long term adverse outcomes.

\section{Abbreviations}

T1D: Type 1 diabetes; DCCT: Diabetes control and complications trial; EDIC: Epidemiology of diabetes interventions and complications; SMBG: Self-monitoring of blood glucose; BNHCS: Brazilian National Health Care System; BrazDiab1SG: Brazilian Type 1 Diabetes Study Group; HbA1c: Glycated hemoglobin; BMI: Body mass index; HPLC: High-performance liquid chromatography; CSII: Continuous subcutaneous insulin infusion.
}

\section{Acknowledgments}

Prof Dr. Gilberto Ney Ottoni de Brito.

\section{Authors' contributions}

MBG wrote, analyzed and reviewed the paper. CAN, LHM wrote and reviewed the paper and LGNM, MHP, BSVB and DCS reviewed the paper. MBG has full access to all study data and takes responsibility for the submission. All authors read and approved the final manuscript.

\section{Funding}

This work was supported by grants from Conselho Nacional de Desenvolvimento Científico e Tecnológico (563753/2010-2) do Brasil and Fundação do Amparo à Pesquisa do Estado do Rio de Janeiro (E-26/111.812/2013).

\section{Availability of data and materials}

Marilia Brito Gomes has full access to data and materials used in this research.

\section{Ethics approval and consent to participate}

This study was approved by the ethics committee of Hospital Universitário Pedro Ernesto. Written informed consent was obtained from all patients.

\section{Consent for publication}

Not applicable.

\section{Competing interests}

The authors declare that they have no competing interests.

\section{Author details}

${ }^{1}$ Diabetes Unit, Department of Internal Medicine, State University Hospital of Rio de Janeiro, Rio de Janeiro, Brazil. ${ }^{2}$ Medical Doctor Program, University of São Paulo-School of Dentistry, Bauru, São Paulo, Brazil.

Received: 23 November 2019 Accepted: 24 January 2020

Published online: 03 February 2020

\section{References}

1. Karvonen M, Viik-Kajander M, Moltchanova E, Libman I, LaPorte R, Tuomilehto J. Incidence of childhood type 1 diabetes worldwide. Diab Care. 2000;23:1516-26.

2. International Diabetes Federation. IDF diabetes atlas. 8th ed. Brussels: International diabetes federation; 2017.

3. American Diabetes Association. Standards of medical care. Diab Care. 2019;42(suppl 1):S13-33.

4. Cobas RA, Ferraz MB, Matheus AS, Tannus LR, Negrato CA, Araujo LA, et al. The cost of type 1 diabetes: a nationwide multicentre study in Brazil. Bull World Health Organ. 2013;91:434-40.

5. American Diabetes Association. Economic cost of diabetes in the U.S. in 2017. Diab Care. 2018;41:917-28.

6. Holman RR, Paul SK, Bethel MA, Matthews DR, Neil HA. 10-year followup of intensive glucose control in type 2 diabetes. N Engl J Med. 2008:359:1577-89.

7. Nathan DM, DCCT/EDIC Research Group. The diabetes control and complications trial/epidemiology of diabetes interventions and complications study at 30 years: overview. Diab Care. 2014;37:9-16.

8. DCCT. The diabetes control and complications trial. N Engl I Med. 1993;329:977-86.

9. Davies MJ, D'Alessio DA, Fradkin J, Kernan WN, Mathieu C, Mingrone $\mathrm{G}$, et al. Management of hyperglycaemia in type 2 diabetes, 2018. A consensus report by the American Diabetes Association (ADA) and the European Association for the study of diabetes (EASD). Diabetologia. 2018;2018(61):2461-98.

10. Willi SM, Miller KM, DiMeglio LA, Klingensmith GJ, Simmons JH, Tamborlane WV, et al. Racial-ethnic disparities in management and outcomes among children with type 1 diabetes. Pediatrics. 2015;135:424-34.

11. Wood JR, Miller KM, Maahs DM, Beck RW, DiMeglio LA, Libman IM, et al. For the TD1 exchange clinic network. Most youth with type 1 diabetes in the T1D exchange clinic registry do not meet american diabetes association or international society for pediatric and adolescent diabetes clinical guidelines. Diab Care. 2013;36:2035-7.

12. The EURODIAB IDDM Complications Study Group. Microvascular and acute complications in IDDM patients: the EURODIAB IDDM complications study. Diabetologia. 1994;37:278-85. 
13. Gomes MB, Charbonnel B, J. Cid-Ruzafa J.Cid, Fenici P, Hammar N, Kamal S et al. Glycaemic, lipid and blood pressure control in 14,391 patients initiating second-line glucose-lowering therapy in 37 countries: results from DISCOVER. EASD. 2018.

14. Gomes MB, Coral M, Cobas RA, Dib SA, Canani LH, Nery M, et al. Prevalence of adults with type 1 diabetes who meet the goals of care in daily clinical practice: a nationwide multicenter study in Brazil. Diab Res Clin Pract. 2012;97:63-70.

15. Gomes MB, Gianella D, Faria M, Tambascia M, Fonseca RM, Rea R, et al. Prevalence of type 2 diabetic patients within the targets of care guidelines in daily clinical practice: a multi-center study in Brazil. Rev Diab Stud. 2006;3:82-7.

16. van Duinkerken E, Schoonheim MM, Steenwijk MD, Klein M, IJzerman RG, Moll AC, et al. Ventral striatum, but not cortical volume loss, is related to cognitive dysfunction in type 1 diabetic patients with and without microangiopathy. Diab Care. 2014;37:2483-90.

17. Malerbi FEK, Negrato CA, Gomes MB. Assessment of psychosocial variables by parents of youth with type 1 diabetes mellitus. Diabetol Metab Syndr. 2012;4:48.

18. Kim H, Elmi A, Henderson CL, Cogen FR, Kaplowitz PB. Characteristics of children with type 1 diabetes and persistent suboptimal glycemic control. J Clin Res Pediatr Endocrinol. 2012;4:82-8.

19. Gomes MB, Negrato CA. Adherence to insulin therapeutic regimens in patients with type 1 diabetes. A nationwide survey in Brazil. Diab Res Clin Pract. 2016;120:47-55.

20. Davison KA, Negrato CA, Cobas R, Matheus A, Tannus L, Palma CS, et al. Brazilian type 1 diabetes study group (BrazDiab1SG). Relationship between adherence to diet, glycemic control and cardiovascular risk factors in patients with type 1 diabetes: a nationwide survey in Brazil. Nutr J. 2014;13:19.

21. Bailey SC, Brega AG, Crutchfield TM, Elasy T, Herr H, Kaphingst K, et al. Update on health literacy and diabetes. Diab Educ. 2014;40:581.

22. McCrimmon RJ, Ryan CM, Frier BM. Diabetes and cognitive dysfunction. Lancet. 2012;379:2291-9.

23. Pesquisa Nacional por amostra de domicílios (PNAD). 2016. https://ww2. ibge.gov.br/home/estatistica/pesquisas/pesquisa_resultados.php?id_ pesquisa=149. Acesso em: 19 de Fevereiro de 2019.

24. Instituto Paulo Montenegro, Ação Educativa. Indicador de Alfabetismo Nacional_INAF/Brasil. 2007. Disponível em: http://www.educacao.salva dor.ba.gov.br/site/documentos/espaco-virtual/espacodados. Acesso em: 19 de Fevereiro de 2019

25. Huang YM, Shiyanbola OO, Smith PD, Chan HY. Quick screen of patients' numeracy and document literacy skills: the factor structure of the Newest Vital Sign. Patient Prefer Adher. 2018;12:853-9.

26. Al Sayah F, Majumdar SR, Williams B, Robertson S, Johnson JA. Health literacy and health outcomes in diabetes: a systematic review. J Gen Intern Med. 2013;28:444-52.

27. Parker RM, Baker DW, Williams MV, Nurss JR. The test of functional health literacy in adults: a new instrument for measuring patients' literacy skills. J Gen Intern Med. 1995;10:537-41.

28. Saeed H, Saleem Z, Naeem R, Shahzadi I, Islam M. Impact of health literacy on diabetes outcomes: a cross-sectional study from Lahore, Pakistan. Public Health. 2018;156:8-14.

29. Morris NS, MacLean CD, Littenberg B. Literacy and health outcomes: across-sectional study in 1002 adults with diabetes. BMC Fam Pract. $2006 ; 7: 49$.
30. Marden S, Thomas PW, Sheppard ZA, Knott J, Lueddeke J, Kerr D. Poor numeracy skills are associated with glycaemic control in type 1 diabetes. Diab Med. 2012;29:662-9.

31. Osborn CY, Cavanaugh K, Wallston KA, Rothman RL. Self-efficacy links health literacy and numeracy to glycemic control. J Health Commun. 2010;15(Suppl 2):146-58.

32. Sampaio HA, Carioca AA, Sabry MO, Dos Santos PM, Coelho MA, Passamai Mda P. Health literacy in type 2 diabetics: associated factors and glycemic control. Cien Saude Colet. 2015;20:865-74

33. Carthery-Goulart MT, Anghinah R, Areza-Fegyveres R, Bahia VS, Brucki SM, Damin A, et al. Performance of a Brazilian population on the test of functional health literacy in adults. Rev Saude Publica. 2009;43:631-8.

34. Ross LA, Frier BM, Kelnar CJ, Deary IJ. Child and parental mental ability and glycaemic control in children with type 1 diabetes. Diab Med. 2001;18:364-9.

35. Dewalt DA, Berkman ND, Sheridan S, Lohr KN, Pignone MP. Literacy and health outcomes: a systematic review of the literature. J Gen Intern Med. 2004;19:1228-39.

36. Cavanaugh K, Huizinga MM, Wallston KA, Gebretsadik T, Shintani A, Davis $D$, et al. Association of numeracy and diabetes control. Ann Intern Med. 2008;148:737-46.

37. Sarkar U, Fisher L, Schillinger D. Is self-efficacy associated with diabetes self-management across race/ethnicity and health literacy? Diab Care. 2006;29:823-9.

38. Mulvaney SA, Lilley JS, Cavanaugh KL, Pittel EJ, Rothman RL. Validation of the diabetes numeracy test with adolescents with type 1 diabetes. J Health Commun. 2013;18:795.

39. Schillinger D, Grumbach K, Piette J, Wang F, Osmond D, Daher C, et al. Association of health literacy with diabetes outcomes. JAMA. 2002;288:475-82.

40. American Diabetes Association. 4. Comprehensive medical evaluation and assessment of comorbidities: standards of medical care in diabetes-2019. Diab Care. 2019;42:34-45.

41. International guide for monitoring alcohol consumption and harm. Department of Mental Health and Substance Dependence/Noncommunicable Diseases and Mental Health Cluster/World Health Organization (2000).

42. Baker DW, Williams MV, Parker RM, Gazmararian JA, Nurss J. Development of a brief test to measure functional health literacy. Patient Educ Couns. 1999:38:33-42.

43. Wachler BS, Krueger RR. Agreement and repeatability of infrared pupillometry and the comparison method. Ophthalmology. 1999;106:319-23.

44. Souza JG, Apolinario D, Magaldi RM, Busse AL, Campora F, Jacob-Filho W. Functional health literacy and glycaemic control in older adults with type 2 diabetes: a cross-sectional study. BMJ Open. 2014;4:004180.

45. Santos FRM, Bernardo V, Gabbay MAL, Dib SA, Sigulem D. impact of knowledge about diabetes, resilience and depression on glycemic control: a crosssectional study among adolescents and young adults with type 1 diabetes. Diab Metab Syndr. 2013;5:55.

\section{Publisher's Note}

Springer Nature remains neutral with regard to jurisdictional claims in published maps and institutional affiliations.

Ready to submit your research? Choose BMC and benefit from

- fast, convenient online submission

- thorough peer review by experienced researchers in your field

- rapid publication on acceptance

- support for research data, including large and complex data types

- gold Open Access which fosters wider collaboration and increased citations

- maximum visibility for your research: over 100M website views per year

At BMC, research is always in progress.

Learn more biomedcentral.com/submissions 